\title{
High temperature-induced triploid production during embryo sac development in Populus
}

\author{
By J. WANG ${ }^{1), 2), 3)}$, X. Y. KANG ${ }^{\left.1), 2), 3),{ }^{*}\right)}$ and D. L. $\mathrm{LI}^{2)}$
}

(Received $20^{\text {th }}$ October 2010)

\begin{abstract}
Triploid breeding plays an important role in cultivar improvement in the genus Populus L. A novel approach for triploid production with colchicine during embryo sac development was reported recently by Wang et al. (2010). In the present investigation, female catkins of Populus pseudo-simonii $\times P$. nigra 'Zheyin3\#' during embryo sac development were exposed to high temperature to assess the effectiveness of high temperature for induction of triploid production. In the progeny, 45 triploids were determined by both flow cytometric analysis and somatic chromosome counting. The period 66-72 $\mathrm{h}$ after pollination was the most suitable for high temperature-induced triploid production during embryo sac development in the 'Zheyin3\#'. Cytological analysis showed that the frequency of eight-nucleate embryo sacs rose at an increased rate during $66-78 \mathrm{~h}$ after pollination, which suggested that the third mitosis during embryo sac development could be the optimal stage for high temperature-induced triploid production. The highest frequency of triploid production was $40 \%$, which was obtained in the $44^{\circ} \mathrm{C}$ for $2 \mathrm{~h}$ treatment $72 \mathrm{~h}$ after pollination. In view of both triploid number and production efficiency, treatments with $41^{\circ} \mathrm{C}$ for $4-6 \mathrm{~h}$ or with $44^{\circ} \mathrm{C}$ for $2 \mathrm{~h}$ during $66-72 \mathrm{~h}$ after pollination were both effective for triploid induction in 'Zheyin3\#'. Statistical analysis showed that the growth of triploids and diploids was not significantly different. However, highly significant differences were observed for all leaf characteristics. Finally, the significance of high temperature treatment in Populus triploid breeding programs is discussed.
\end{abstract}

Key words: $2 n$ egg, embryo sac development, high temperature, Populus, triploid

\section{Introduction}

In China, poplar plantations cover more than 7 million $\mathrm{hm}^{2}$ lands and make a significant contribution to the wood industry (FANG, 2008). Some allotriploid poplars, such as $P$. $\times$ canadensis 'I-214', $P . \times$ euramericana 'Zhonglin-46', P. × canadensis 'Sacrau 79',

1) National Engineering Laboratory for Tree Breeding, Beijing Forestry University, 100083, Beijing, People's Republic of China.

$\left.{ }^{2}\right)$ Key Laboratory of Genetics and Breeding in Forest Trees and Ornamental Plants, MOE, Beijing Forestry University, 100083, Beijing, People's Republic of China.

3) College of Biological Sciences and Biotechnology, Beijing Forestry University, 100083, Beijing, People's Republic of China.

*) P. O. Box 118, Beijing Forestry University, NO.35, Tsinghua East Rd., Haidian District, 100083, Beijing, People's Republic of China; Tel.: +86-10-62336168; E-mail: kangxy@bjfu.edu.cn
P. $\times$ euramericana 'Wuhei-1', $P . \times$ liaohenica, $P . \times$ langfangensis-3 and triploid clones of $P$. tomentosa (ZHU et al., 1995; ZHANG et al., 2004, 2005), have been wildly used for plantations in China, owing to their favourable growth and pulpwood characteristics. Therefore, triploid breeding plays an important role in cultivar improvement in the genus Populus L.

To produce triploid Populus, many methods have been developed, such as crossing diploid plants with triploids or tetraploids (WINTON and EINSPAHR, 1970; HARDER et al., 1976; BAUMEISTER, 1980; EINSPAHR, 1984), utilization of spontaneous or induced diploid ( $2 n$ ) pollen (JOHNSSON and EkLundH, 1940; SeITZ, 1954; MANZOS, 1960; MASHKINA et al., 1989; ZHU et al., 1995; KANG et al., 2000b), and hybridization with artificial $2 n$ female gametes (LI et al., 2008; WANG et al., 2010), but, most of these techniques are not efficient for triploid production. WANG et al. (2010) reported a novel method for triploid induction by treatment of developing embryo sacs with colchicine solution, which showed high triploid production efficiency $(66.7 \%)$. However, seed production was affected because of the toxicity of colchicine and just 23 triploid hybrids were obtained. Furthermore, application of colchicine treatments is complicated and time-consuming. Therefore, an alternative agent for triploid induction during embryo sac development is required.

High temperature, as a physical mutagenic agent, is often applied to induce polyploid in plants and animals (RANDOLPH, 1932; MASHKINA et al., 1989; KANG et al., 2000a; ZHANG et al., 2002; NomURA et al., 2004; YANG and Guo, 2006; WANG et al., 2012). In Populus, $2 n$ pollen was induced successfully with high temperature by MASHKINA et al. (1989) and KANG et al. (2000a), and the frequency of artificial $2 n$ pollen exceeded $80 \%$. In this investigation, female catkins of $P$. pseudo-simonii $\times P$. nigra 'Zheyin3\#' during embryo sac development were exposed to high temperature, in order to assess the effectiveness of high temperature treatment for triploid induction in Populus.

\section{Materials and Methods}

\section{Plant materials}

Floral branches of $P$. pseudo-simonii $\times P$. nigra 'Zheyin3\#' (female parent, $2 n=2 x=38$ ) were collected from a plantation in Tongliao city (Inner Mongolia Autonomous Region, People's Republic of China). Floral branches of $P$. $\times$ beijingensis (male parent, $2 n=2 x=38$ ) were collected on the campus of Beijing Forestry University. The branches were water-cultured in a greenhouse $\left(10-20^{\circ} \mathrm{C}\right)$ for subsequent use. 


\section{Treatment with high temperature}

According to WANG et al. (2010), stigma receptivity of 'Zheyin3\#' catkins can be evaluated through their length and developmental status. When female catkins of 'Zheyin3\#' attained optimal receptivity, they were pollinated with fresh pollen of $P$. $\times$ beijingensis. At $36-78 \mathrm{~h}$ after pollination, the catkins were exposed to $38^{\circ} \mathrm{C}$, $41^{\circ} \mathrm{C}$ or $44^{\circ} \mathrm{C}$ in a thermo chamber for $2 \mathrm{~h}, 4 \mathrm{~h}$ or $6 \mathrm{~h}$. In all treatments, the relative humidity in the thermo chamber was set as $50 \%$. Before treatment, three female catkins were fixed with FAA ( $70 \%$ ethanol: acetic acid: $40 \%$ formaldehyde, 90:5:5) for further determination of embryo sac development and a total of 24 catkins were collected. Untreated catkins were set as a control.

After treatment, the catkins were water-cultured in the greenhouse until seed maturation. Subsequently, seeds were harvested and germinated in soil. When the seedlings grew to about $30 \mathrm{~cm}$ in height, they were transplanted to the field, following which the ploidy level of each seedling was determined.

\section{Cytological observation of embryo sac development}

After removal of the fixed female catkins from the fixtive, 10 ovaries were randomly excised from each catkin for cytological analysis. A total of 240 ovaries were collected. The ovaries were embedded in paraffin and sections of $8-10 \mu \mathrm{m}$ thickness were cut. The sections were stained with iron-hematoxylin and observed with an Olympus BX51 microscope.

\section{Determination of ploidy level}

Flow cytometry was first used to screen putative polyploids in progeny. Young leaves from the seedlings were chopped on ice in modified Galbraith's buffer $(45 \mathrm{mM}$ $\mathrm{MgCl}_{2} \cdot 6 \mathrm{H}_{2} \mathrm{O}, 20 \mathrm{mM}$ MOPS, $30 \mathrm{mM}$ sodium citrate, $0.5 \%$ Triton $\mathrm{X}-100,1 \%$ PVP-10, $\mathrm{pH} 7.0$ ) using a sharp razor blade following the method of GALBRAITH et al.
(1983). The nuclear suspension was filtered through a $40-\mu \mathrm{m}$ nylon mesh to remove large debris. Nuclei were stained with $50 \mu \mathrm{g} \mathrm{mL}-1$ propidium iodide with $50 \mu \mathrm{g}$ $\mathrm{mL}^{-1}$ RNase. After incubation on ice for $30 \mathrm{~min}$ in dark, samples were analyzed with a BD FACSCalibur flow cytometer. A known diploid plant from the progeny was analyzed as internal criteria.

After flow cytometric analysis, the ploidy levels of all putative triploid plants were confirmed by somatic chromosome counting. Stem tips were removed from the seedlings and pretreated with a saturated solution of paradichlorobenzene for $4 \mathrm{~h}$ at $25^{\circ} \mathrm{C}$. Subsequently, the materials were fixed in fresh Farmer's solution (ethanol: acetic acid, 3:1) for $24 \mathrm{~h}$ at $4^{\circ} \mathrm{C}$, and then hydrolyzed in $38 \% \mathrm{HCl}$ : ethanol (1:1) for $25 \mathrm{~min}$ at room temperature. After washing in distilled water three times for $15 \mathrm{~min}$ each, the hydrolyzed materials were squashed in carbol fuchsin solution. Chromosome counts for at least 20 cells with a well-spread metaphase per seedling were observed using an Olympus BX51 microscope.

\section{Leaf analysis and growth measurement of seedlings}

All triploid and 50 randomly selected diploid seedlings were used to analyze differences in morphological and growth characteristics, including leaf area, leaf length (including petiole) and width, leaf shape index (length/width), number of sawteeth on the leaf margin, stem height, and basal diameter of seedlings. For leaf analysis, the seventh, eighth and ninth mature leaves from the shoot tip were selected for measurement with a LI-3000A portable leaf area meter (LI-COR, USA). The average area, length, width, shape index and number of marginal sawteeth of leaves of each plant were calculated. After the seedlings stopped growing in early winter, stem height and basal diameter of the plants were measured in the experimental field. The data were analyzed with unpaired $t$-tests.
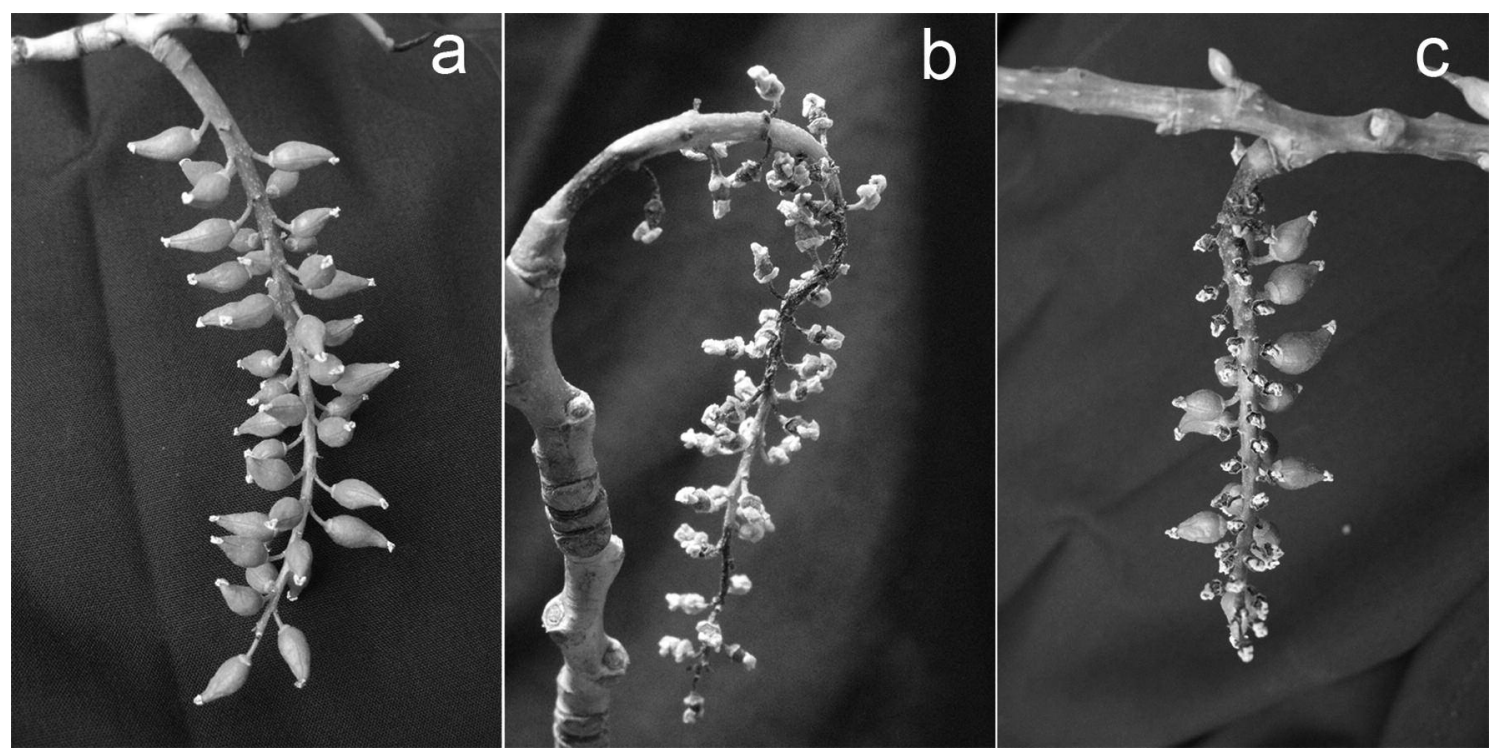

Figure 1. - Comparison of normal pollinated and high-temperature-treated female catkins of $P$. pseudosimonii $\times$ P. nigra 'Zheyin3\#'.

a. Normally developed pollinated female catkin; b. Aborted high-temperature treated catkin; c. Surviving hightemperature-treated catkin. 


\section{Results}

Effect of high temperature on female catkins

High temperature damaged the development of female catkins. Compared with untreated catkins (Fig. 1a), the peduncle of treated catkins turned to brown and its pistils and ovaries became shrivelled. With increased temperature, the number of mature seeds decreased. Some catkins even died (Fig. 1b) owing to excessive injury induced by high temperature, which resulted in no seed production in some treatments. Treatments with $44^{\circ} \mathrm{C}$ and $6 \mathrm{~h}$ duration usually injured catkins more severely than that with $38^{\circ} \mathrm{C}$ and $2 \mathrm{~h}$ duration. However, most catkins still survived even though some ovaries were aborted (Fig. 1c).

\section{Triploid production induced by high temperature}

In the offspring with 1908 seedlings, 45 triploids were determined by flow cytometric analysis and somatic chromosome counting (Fig. 2). No triploids were found in the control group, which suggested that neither spontaneous $2 n$ eggs formed nor natural $2 n$ eggs or $2 n$ pollen take part in fertilization under a standard temperature.

Treatment of pollinated female catkins 36-78 h after pollination with high temperature induced triploid production (Table 1). However, the efficiency of triploid production differed among the treatments. In treatments 66-72 $\mathrm{h}$ after pollination, 30 triploid hybrids were obtained, which accounted for $66.7 \%$ of the total triploid number. Thus, female catkins $66-72 \mathrm{~h}$ after pollination could be the most suitable for triploid production with high temperature. The highest frequency of triploid pro- duction was $40 \%$, which was observed in the $44{ }^{\circ} \mathrm{C}$ for $2 \mathrm{~h}$ treatment $72 \mathrm{~h}$ after pollination. Although $100 \%$ triploid production was obtained in the $41^{\circ} \mathrm{C}$ for $6 \mathrm{~h}$ treatment $60 \mathrm{~h}$ after pollination, only one seedling survived and thus the frequency might be unrepresentative.

The efficiency of triploid production was associated with the temperature and duration of treatment. With increased temperature and duration of treatment, the triploid production efficiency was increased. Taking the treatments $72 \mathrm{~h}$ after pollination as an example, when temperature was elevated from $38^{\circ} \mathrm{C}$ to $44^{\circ} \mathrm{C}$, the frequency of triploid production increased from $2.35 \%$ to $40.00 \%$; when the duration of treatment was extended from $2 \mathrm{~h}$ to $6 \mathrm{~h}$ in treatments with $41^{\circ} \mathrm{C}$, the triploid production efficiency was doubled. However, a higher temperature or duration of treatment was not more effective owing to excessive induction of injury. Therefore, in terms of both triploid number and production efficiency, we considered treatment with $41^{\circ} \mathrm{C}$ for $4-6 \mathrm{~h}$ or with $44^{\circ} \mathrm{C}$ for $2 \mathrm{~h}$ were the most effective for triploid induction.

\section{Effective treatment stage for high temperature-induced triploid production}

The embryo sac development of 'Zheyin3\#' was of the typical Polygonum type. The functional megaspore formed a 7-celled mature embryo sac via three rounds of mitotic divisions (Fig. 3). Although asynchronous embryo sac development was observed, the predominant developmental stage successively changed from a twonucleate sac to an eight-nucleate sac with time after pol-
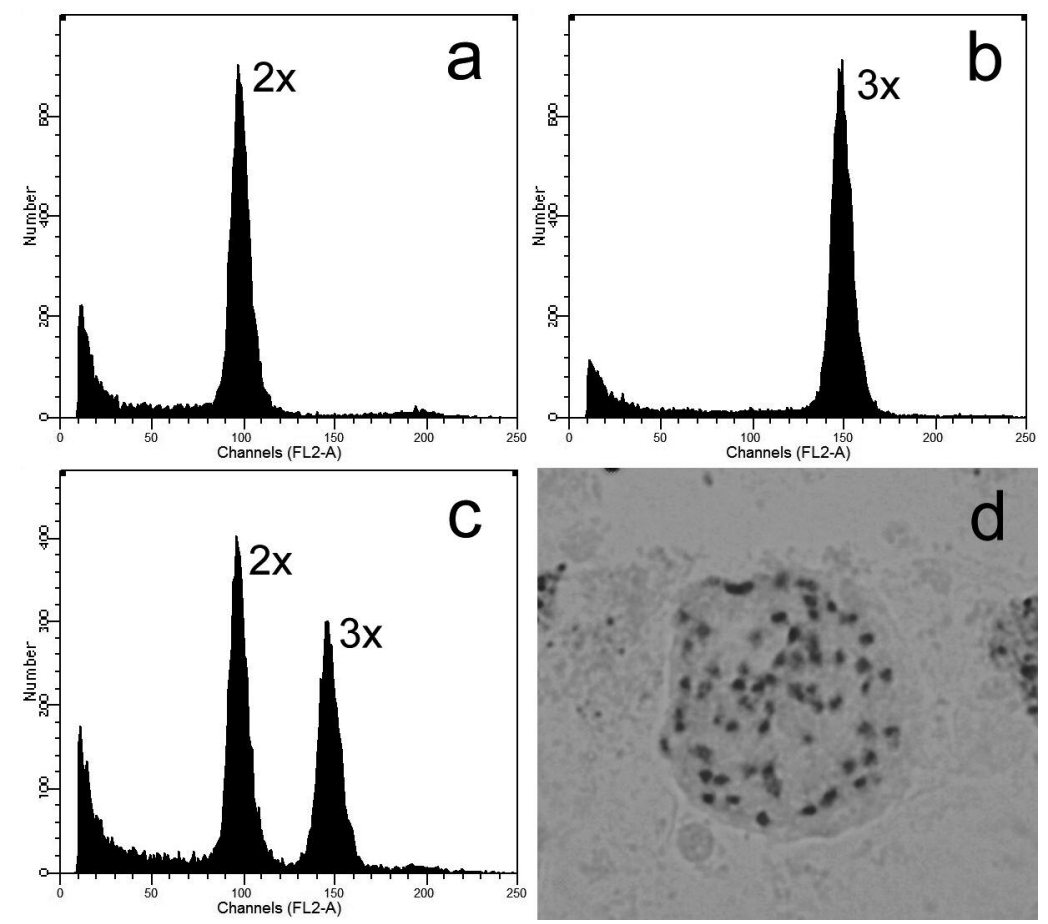

Figure 2. - Ploidy level determination of offspring.

Flow cytometric analysis of a diploid plant (a), a triploid plant (b) and mixed nuclei of the former diploid and triploid plants (c); d. Somatic chromosomes of a triploid plant with $2 n=3 x=57$. 
Table 1. - Triploid production resulting from high-temperature-induced chromosome doubling in the embryo sacs of $P$. pseudo-simonii $\times$ P. nigra 'Zheyin3\#'.

\begin{tabular}{|c|c|c|c|c|c|c|}
\hline $\begin{array}{l}\text { Hours after } \\
\text { pollination }\end{array}$ & $\begin{array}{l}\text { Temperature of } \\
\text { treatment }\left({ }^{\circ} \mathrm{C}\right)\end{array}$ & $\begin{array}{l}\text { Duration of } \\
\text { treatment (h) }\end{array}$ & $\begin{array}{l}\text { No. of } \\
\text { seeds }\end{array}$ & $\begin{array}{c}\text { No. of } \\
\text { seedlings }\end{array}$ & $\begin{array}{l}\text { No. of } \\
\text { triploids }\end{array}$ & $\begin{array}{c}\text { Rate of } \\
\text { triploids (\%) }\end{array}$ \\
\hline \multirow{9}{*}{36} & \multirow{3}{*}{38} & 2 & 239 & 89 & 0 & 0 \\
\hline & & 4 & 155 & 70 & 0 & 0 \\
\hline & & 6 & 96 & 41 & 0 & 0 \\
\hline & \multirow{3}{*}{41} & 2 & 16 & 15 & 2 & 13.33 \\
\hline & & 4 & 29 & 5 & 0 & 0 \\
\hline & & 6 & 22 & 13 & 1 & 7.69 \\
\hline & \multirow{3}{*}{44} & 2 & 14 & 3 & 0 & 0 \\
\hline & & 4 & 12 & 0 & - & - \\
\hline & & 6 & 0 & - & - & - \\
\hline \multirow{9}{*}{42} & \multirow{3}{*}{38} & 2 & 103 & 43 & 0 & 0 \\
\hline & & 4 & 55 & 11 & 0 & 0 \\
\hline & & 6 & 31 & 12 & 0 & 0 \\
\hline & \multirow{3}{*}{41} & 2 & 19 & 7 & 1 & 14.29 \\
\hline & & 4 & 16 & 9 & 0 & 0 \\
\hline & & 6 & 6 & 1 & 0 & 0 \\
\hline & \multirow{3}{*}{44} & 2 & 10 & 1 & 0 & 0 \\
\hline & & 4 & 47 & 10 & 1 & 10.00 \\
\hline & & 6 & 0 & - & - & - \\
\hline \multirow[t]{9}{*}{48} & \multirow{4}{*}{38} & 2 & 154 & 102 & 0 & 0 \\
\hline & & 4 & 51 & 24 & 0 & 0 \\
\hline & & 6 & 52 & 17 & 0 & 0 \\
\hline & & 2 & 44 & 30 & 1 & 3.33 \\
\hline & \multirow[t]{2}{*}{41} & 4 & 54 & 10 & 0 & 0 \\
\hline & & 6 & 59 & 8 & 1 & 12.50 \\
\hline & \multirow[t]{3}{*}{44} & 2 & 0 & - & - & - \\
\hline & & 4 & 0 & - & - & - \\
\hline & & 6 & 0 & - & - & - \\
\hline \multirow{9}{*}{54} & \multirow{3}{*}{38} & 2 & 46 & 16 & 0 & 0 \\
\hline & & 4 & 128 & 41 & 0 & 0 \\
\hline & & 6 & 73 & 45 & 0 & 0 \\
\hline & \multirow{3}{*}{41} & 2 & 76 & 38 & 1 & 2.63 \\
\hline & & 4 & 33 & 3 & 0 & 0 \\
\hline & & 6 & 43 & 10 & 0 & 0 \\
\hline & \multirow{3}{*}{44} & 2 & 10 & 0 & - & - \\
\hline & & 4 & 32 & 1 & 0 & 0 \\
\hline & & 6 & 0 & - & - & - \\
\hline
\end{tabular}


Table 1. - Continued.

\begin{tabular}{|c|c|c|c|c|c|c|}
\hline & & 2 & 113 & 1 & 0 & 0 \\
\hline & 38 & 4 & 114 & 23 & 1 & 4.35 \\
\hline & & 6 & 100 & 20 & 0 & 0 \\
\hline & & 2 & 86 & 6 & 0 & 0 \\
\hline \multirow[t]{9}{*}{60} & 41 & 4 & 50 & 17 & 1 & 5.82 \\
\hline & & 6 & 91 & 1 & 1 & 100.00 \\
\hline & & 2 & 0 & - & - & - \\
\hline & 44 & 4 & 0 & - & - & - \\
\hline & & 6 & 0 & - & - & - \\
\hline & & 2 & 263 & 52 & 0 & 0 \\
\hline & 38 & 4 & 219 & 67 & 1 & 1.49 \\
\hline & & 6 & 77 & 31 & 0 & 0 \\
\hline & & 2 & 75 & 12 & 0 & 0 \\
\hline \multirow[t]{9}{*}{66} & 41 & 4 & 104 & 46 & 5 & 10.87 \\
\hline & & 6 & 87 & 53 & 11 & 20.75 \\
\hline & & 2 & 13 & 3 & 1 & 33.33 \\
\hline & 44 & 4 & 0 & - & - & - \\
\hline & & 6 & 0 & - & - & - \\
\hline & & 2 & 330 & 173 & 1 & 0.58 \\
\hline & 38 & 4 & 130 & 47 & 0 & 0 \\
\hline & & 6 & 131 & 85 & 2 & 2.35 \\
\hline & & 2 & 53 & 28 & 2 & 7.14 \\
\hline \multirow[t]{9}{*}{72} & 41 & 4 & 58 & 30 & 2 & 6.67 \\
\hline & & 6 & 112 & 21 & 3 & 14.29 \\
\hline & & 2 & 27 & 5 & 2 & 40.00 \\
\hline & 44 & 4 & 2 & 0 & - & - \\
\hline & & 6 & 0 & - & - & - \\
\hline & & 2 & 240 & 93 & 0 & 0 \\
\hline & 38 & 4 & 82 & 58 & 0 & 0 \\
\hline & & 6 & 146 & 62 & 1 & 1.61 \\
\hline & & 2 & 187 & 37 & 0 & 0 \\
\hline \multirow[t]{5}{*}{78} & 41 & 4 & 153 & 42 & 2 & 4.76 \\
\hline & & 6 & 60 & 2 & 0 & 0 \\
\hline & & 2 & 69 & 4 & 1 & 25.00 \\
\hline & 44 & 4 & 0 & - & - & - \\
\hline & & 6 & 7 & 0 & - & - \\
\hline Control & & & 398 & 214 & 0 & 0 \\
\hline Total & & & 5302 & 1908 & 45 & \\
\hline
\end{tabular}




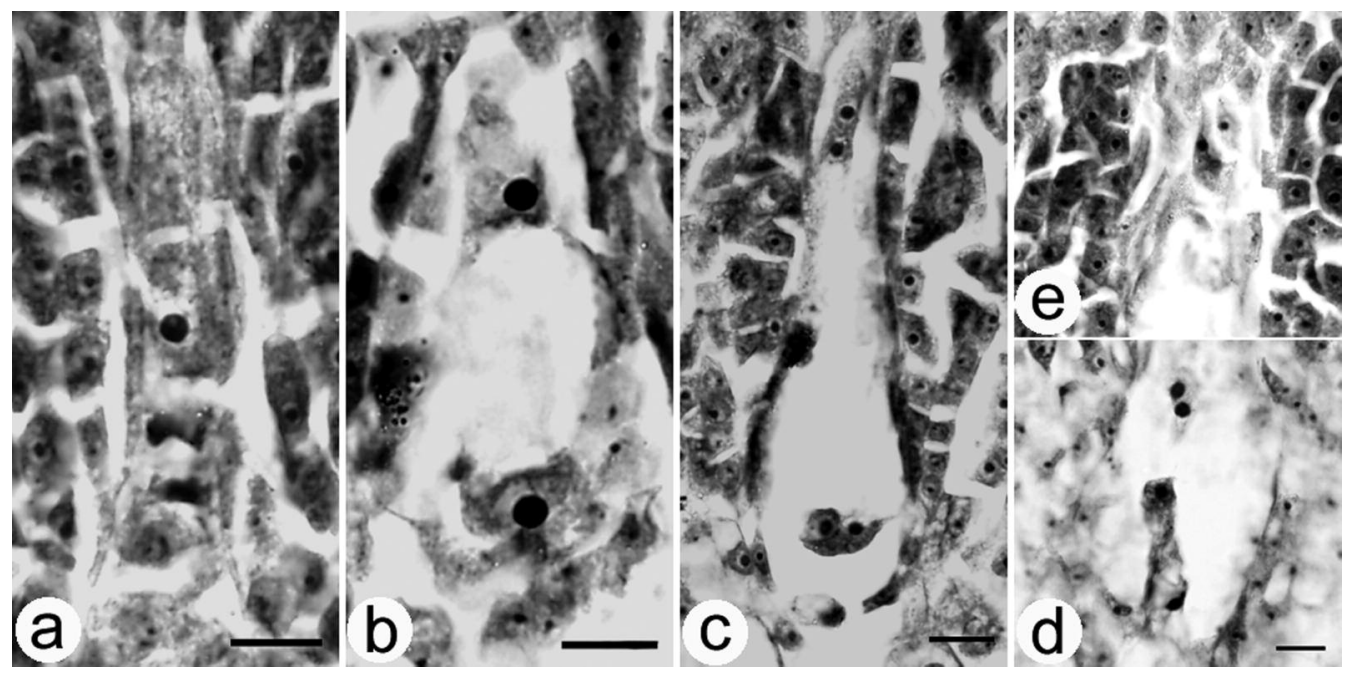

Figure 3. - Embryo sac development of $P$. pseudo-simonii $\times P$. nigra 'Zheyin3\#'. The chalazal end is at the top in all figures. Bars $=10 \mu \mathrm{m}$.

a. Uni-nucleate embryo sac with three degenerated megaspores; b. Two-nucleate embryo sac; c. Four-nucleate embryo sac; $d$ and e. Serial sections showing mature embryo sac with a 7-celled, 8 nucleate structure.

Table 2. - Analysis of embryo sac development stages after pollination in P. pseudo-simonii $\times$ P. nigra 'Zheyin3\#'.

\begin{tabular}{ccccccc}
\hline \multirow{2}{*}{$\begin{array}{c}\text { Hours } \\
\text { after }\end{array}$} & \multicolumn{5}{c}{ Percentage of each stage (\%) } \\
\cline { 2 - 7 } pollination & Tetrad & $\begin{array}{c}\text { Uni-nucleate } \\
\text { embryo sac }\end{array}$ & $\begin{array}{c}\text { Two-nucleate } \\
\text { embryo sac }\end{array}$ & $\begin{array}{c}\text { Four-nucleate } \\
\text { embryo sac }\end{array}$ & $\begin{array}{c}\text { Eight-nucleate } \\
\text { and mature } \\
\text { embryo sac }\end{array}$ & Fertilization \\
\hline 36 & 1.55 & 10.08 & 27.13 & 32.56 & 28.68 & \\
42 & & 7.94 & 32.54 & 28.57 & 30.95 & \\
48 & 1.98 & 10.89 & 28.71 & 30.69 & 27.72 & \\
54 & & 8.51 & 24.47 & 36.17 & 30.85 & \\
60 & & 8.82 & 17.65 & 41.18 & 32.35 & \\
66 & & 6.93 & 16.83 & 35.64 & 40.59 & 2.33 \\
72 & & & 13.18 & 35.66 & 48.84 & \\
78 & & & 11.65 & 30.10 & 55.34 & 2.91 \\
\hline
\end{tabular}

lination (Table 2). In catkins between $66 \mathrm{~h}$ and $78 \mathrm{~h}$ after pollination, the frequency of eight-nucleate embryo sacs rose at an increased rate, which indicated more four-nucleate sacs developed into eight-nucleate sacs in this period. Therefore, the third mitotic division during embryo sac development could be the optimal stage for triploid induction with high temperature.

\section{Comparative growth and morphology of triploid and diploid seedlings}

The range of variation for all characters was large among individuals of the same ploidy level (Table 3), which indicated character segregation was common in the $\mathrm{F}_{1}$ generation. Unpaired $t$-tests revealed that the stem height and basal diameter of triploids and diploids did not differ significantly $(t=0.2667$, $P=0.7903$ and $t=1.5482, P=0.1256$, respectively). However, all of the leaf characteristics, i.e. the leaf area, leaf length and width, leaf shape index and the number of marginal sawteeth, were highly significantly different between triploids and diploids $(t=3.6451$, $P=0.0004 ; \quad t=2.9979, \quad P=0.0035 ; \quad t=4.2461$, $P=0.0001 ; \quad t=3.1601, \quad P=0.0022 ; \quad$ and $t=4.1308$, $P=0.0001$, respectively). 
Table 3. - Comparison of growth and leaf characteristics of triploid and diploid offspring of ( $P$. pseudo-simonii $\times$ P. nigra 'Zheyin3\#') $\times$. $\times$ beijingensis.

\begin{tabular}{|c|c|c|c|c|c|c|}
\hline \multirow{2}{*}{ Characters } & \multicolumn{2}{|c|}{ Triploids } & \multicolumn{2}{|c|}{ Diploids } & \multirow{2}{*}{$t$-value } & \multirow{2}{*}{$P$-value } \\
\hline & Range & Mean \pm SE & Range & Mean \pm SE & & \\
\hline Stem height $(\mathrm{cm})$ & $64.0-312.0$ & $191.2 \pm 8.1$ & $62.0-298.7$ & $188.4 \pm 6.4$ & 0.2667 & 0.7903 \\
\hline $\begin{array}{l}\text { Basal diameter } \\
(\mathrm{cm})\end{array}$ & $0.65-2.53$ & $1.66 \pm 0.07$ & $0.83-2.85$ & $1.53 \pm 0.05$ & 1.5482 & 0.1256 \\
\hline Leaf area $\left(\mathrm{cm}^{2}\right)$ & $38.99-228.97$ & $121.02 \pm 6.45$ & $33.60-175.07$ & $90.86 \pm 5.29$ & $3.6451 * *$ & 0.0004 \\
\hline Leaf length $(\mathrm{cm})$ & $10.71-25.33$ & $18.47 \pm 0.54$ & $9.84-21.42$ & $16.31 \pm 0.48$ & $2.9979 * *$ & 0.0035 \\
\hline Leaf width $(\mathrm{cm})$ & $7.50-19.94$ & $13.48 \pm 0.38$ & $5.84-17.44$ & $11.21 \pm 0.37$ & $4.2461 * *$ & 0.0001 \\
\hline $\begin{array}{l}\text { Leaf shape index } \\
\text { (length/width) }\end{array}$ & $1.13-1.70$ & $1.38 \pm 0.02$ & $1.15-1.96$ & $1.47 \pm 0.02$ & $3.1601 * *$ & 0.0022 \\
\hline $\begin{array}{c}\text { Number of leaf } \\
\text { sawtooth }\end{array}$ & $60.00-134.67$ & $85.42 \pm 2.54$ & $62.33-159.67$ & $102.13 \pm 3.08$ & $4.1308 * *$ & 0.0001 \\
\hline
\end{tabular}

** Significant difference between triploids and diploids at $P=0.01$ in unpaired $t$-test.

\section{Discussion}

Selection of mutagenic agents is important for polyploid breeding programs in plants. Colchicine is the most popular anti-microtubule agent for polyploid induction in plants (YeMETS and BLUME, 2008). In previous studies on sexual polyploidization of plants, colchicine was used successfully to induce $2 n$ pollen and $2 n$ eggs (JoHNSSON and EkLundH, 1940; LEBEDEFF, 1940; KANG et al., 1999; Gu and LuO, 2003; Wu et al., 2007; LI et al., 2008; WANG et al., 2010). However, novel mutagenic agents, such as trifluralin, oryzalin, temperature and nitrous oxide, were applied to induce $2 n$ gamete formation (MASHKINA et al., 1989; NEGRI and LEMMI, 1998; KATO, 1999; KANG et al., 2000a; HUANG et al., 2002; ZHANG et al., 2002; BARBA-GONZALEZ et al., 2006; AKUTSA et al., 2007; Dewitte et al., 2010; WANG et al., 2012), owing to the high cost and toxicity of colchicine. High temperature, as an atoxic physical agent, is especially favourable for polyploid breeding because of its operational advantages and uniformity of treatments. MASHKINA et al. (1989) and KANG et al. (2000a) induced more than $80 \%$ artificial $2 n$ pollen with high temperature in $P$. alba and P. tomentosa $\times$ P. bolleana respectively. In our study, 45 triploid hybrids were produced, suggesting that high temperature treatment is effective for triploid production during embryo sac development of Populus.

The mechanism of high-temperature-induced $2 n$ pollen formation has been studied frequently, owing to the ease of observation of male gamete development. High temperature treatment usually results in meiotic abnormalities, including synapsis failure, chromosome stickiness and laggards (MALIK, 1960; HAN et al., 1996). In Populus and Rosa, KANG et al. (2000a) and PÉCRIX et al. (2011) respectively found that high-temperatureinduced spindle misorientations in the second meiotic division led to production of dyads and triads, which developed into $2 n$ pollen grains. Moreover, high temperature could inhibit cell plate formation, which caused aberrant cytokinesis (KANG et al., 2000a). However, because abnormal development of female gametes within the ovules is difficult to monitor, the mechanisms responsible for high-temperature-induced $2 n$ egg formation remain uncertain.
In general, the effective stages for gamete chromosome doubling differ between colchicine and high-temperature treatment. In $2 n$ pollen induction of Populus, the pachytene stage during microsporogenesis is the most suitable stage for colchicine treatment (KANG et al., 1999), whereas the optimal stage for high-temperature treatment was diakinesis (KANG et al., 2000a), which is later than pachytene. In the present study, the third mitotic division during embryo sac development was concluded to be the optimal stage for high-temperature-induced triploid production, which identical to that with colchicine treatment (WANG et al., 2010). However, the period for efficient triploid production with high temperature (66-72 $\mathrm{h}$ after pollination) is slightly later than that with colchicine (54-66 $\mathrm{h}$ after pollination), possibly because diffusion of colchicine solution inside the ovule is slower than the conduction of heat.

So far, although $2 n$ eggs were induced by treatment of developing embryo sacs both with colchicine and high temperature, subsequent development of the treated embryo sacs remains elusive. Recently, FRIEDMAN and WiLLIAMs (2004) discovered that the female gametophyte in the earliest flowering plants probably was not of the Polygonum type but rather was four-celled and four-nucleate at maturity, which suggests that fournucleate embryo sacs might possess the capability for fertilization. In studies of $2 n$ egg induction during embryo sac development, the third mitotic division during embryo sac development was inhibited, which resulted in production of embryo sacs with $2 n$ eggs. The $2 n$ eggs either take part in fertilization directly or undergo an additional mitotic division, which should be investigated further by cytological analysis.

Irrespective of treatment with either colchicine or high temperature, $2 n$ eggs produced by treatment of developing embryo sacs are homozygous owing to inhibition of mitotic division. The significance of homozygous $2 n$ eggs in plant breeding programs, including genetic research and new germplasm production, was discussed by WANG et al. (2010). The triploids produced by WANG et al. (2010) and in this study provided new germplasm for both cultivar selection and genetic improvement of Populus. 
In previous studies on polyploid induction, polyploids derived from somatic chromosome doubling usually show superior characteristics over their diploid counterparts, such as larger leaves and flowers (Gu et al., 2005; Allum et al., 2007). In addition to environmental factors, polyploid phenotypes depend on genomic structure and polyploidy effects. Since somatic chromosome doubling does not change the genomic structure, the phenotypic variation should be attributable to additional copies of existing genes and their functional diversification. In this investigation, sexual polyploidization involved in $2 n$ egg induction during embryo sac development produced a triploid population. The genomic structure of these triploids differed both among each triploid and with their diploid parents owing to genetic recombination, and consequently the average growth of the triploid population was not significantly different from that of the diploid population. However, some superior individuals that exhibit both heterosis and ploidy vigor could be screened, so it is necessary to conduct further genetic tests of the triploid population.

\section{Acknowledgements}

The authors thank the Forestry Research Institute of Tongliao City, the Inner Mongolia Autonomous Region, People's Republic of China, for collecting the plant materials. We also thank MIN LU, a graduate student in Beijing Forestry University, for her help in hybridization of Populus. This work was supported by the Fundamental Research Funds for the Central Universities (Grant No. BL HJ2010-15) and the National Natural Science Foundation of China (Grant No. 31000306).

\section{References}

Akutsu, M., S. Kitamura, R. Toda, I. Miyajima and K. OKAZAKI (2007): Production of $2 n$ pollen of Asiatic hybrid lilies by nitrous oxide treatment. Euphytica 155: 143-152.

Allum, J., D. Bringloe and A. Roberts (2007): Chromosome doubling in a Rosa rugosa Thunb. hybrid by exposure of in vitro nodes to oryzalin: the effects of node length, oryzalin concentration and exposure time. Plant Cell Rep 26(11): 1977-1984.

Barba-Gonzalez, R., C. Miller, M. Ramanna and J. van TUYL (2006): Nitrous oxide $\left(\mathrm{N}_{2} \mathrm{O}\right)$ induces $2 n$ gametes in sterile $\mathrm{F}_{1}$ hybrids between Oriental $\times$ Asiatic lily ( Lili$u m$ ) hybrids and leads to intergenomic recombination. Euphytica 148: 303-309.

BAumeister, G. (1980): Beispiele der polyploidie-Züchtung. Allg Forestz 35: 697-699.

Dewitte, A., T. Eeckhaut, J. van Huylenbroeck and E. VAN BOCKSTAELE (2010): Induction of $2 n$ pollen formation in Begonia by trifluralin and $\mathrm{N}_{2} \mathrm{O}$ treatments. Euphytica 171: 283-293.

EINSPAHR, D. W. (1984): Production and utilization of triploid hybrid aspen. Iowa State J Res 58: 401-409.

FANG, S. Z. (2008): Silviculture of poplar plantation in China: a review. Chin J Appl Ecol 19(10): 2308-2316.

Friedman, W. E. and J. H. Williams (2004): Developmental evolution of the sexual process in ancient flowering plant lineages. The Plant Cell 16: 119-132.
Galbraith, D. W., K. R. Harkins, J. M. Maddox, N. M. Ayres, D. P. Sharma and E. Firoozabady (1983): Rapid flow cytometric analysis of the cell cycle in intact plant tissues. Science 220: 1049-1051.

Gu, X. F., A. F. YANG, H. MENG and J. R. Zhang (2005): In vitro induction of tetraploid plants from diploid Zizyphus jujuba Mill. cv. Zhanhua. Plant Cell Rep 24(11): 671-676.

Gu, X. F. and Z. R. Luo (2003): Study on pollen chromosome doubling in Zenjimaru persimmon. Scientia Agricultura Sinica 36: $426-418$.

HaN, X. B., R. Q. Li, J. B. WANG and C. MiAo (1996): Effect of heat stress on pollen development and pollen viability of pepper. Acta Horticulturae Sinica 23(4): 359-364.

Harder, M. L., S. Verhagen, L. Winton and D. W. EINSPAHR (1976): Tetraploid aspen production using unreduced pollen from triploid males. For Sci 22: 329-330.

HuANG, Q. J., Z. Y. ZHANG and X. Y. KANG (2002): $2 n$ pollen of $P$. tomentosa $\times P$. bolleana induced by four antimicrotubule agents. J Beijing For Univ 24: 12-15.

Johnsson, H. and C. EKLundH (1940): Colchicine treatment as a method in breeding hardwood species. Svensk Papp Tidn 43: 373-377.

KanG, X. Y., Z. T. ZHU and Z. Y. Zhang (2000a): Suitable period of high temperature treatment for $2 n$ pollen of Populus tomentosa $\times$ P. bolleana. J Beijing For Univ 22: $1-4$.

KANG, X. Y., Z. T. ZhU and Z. Y. ZhANG (2000b): Breeding of triploids by the reciprocal crossing of Populus alba $\times$ $P$. glandulosa and $P$. tomentosa $\times P$. bolleana. J Beijing For Univ 22: 8-11.

KANG, X. Y., Z. T. ZHU and H. B. LiN (1999): Study on the effective treating period for pollen chromosome doubling of Populus tomentosa $\times P$. bolleana. Sci Silvae Sinicae 35: 21-24.

KATO, A. (1999): Induction of bicellular pollen by trifluralin treatment and occurrence of triploids and aneuploids after fertilization in maize. Genome 42: 154-157.

LEBEDEFF, G. A. (1940): Failure of cytokinesis during microsporogenesis in Zea mays following heat treatment. Cytologia 10: 434-442.

LI, Y. H., X. Y. KANG, S. D. WANG, Z. H. Zhang and H. W. CHen (2008): Triploid induction in Populus alba $\times$ $P$. glandulosa by chromosome doubling of female gametes. Silvae Genet 57: 37-40.

MALIK, C. P. (1960): Effect of variations in temperature on meiosis in Gagea reticulata Schultes. Nature 187 (4739): 805-806.

Manzos, A. M. (1960): Fast-growing form of Populus balsamifera obtained by pollinating female flowers with fractionated pollen of the same species. Dokl Akad Nauk SSSR 130: 433-435.

Mashkina, O. S., L. M. Burdaeva, M. M. Belozerova and L. N. Vyunova (1989): Method of obtaining diploid pollen of woody species. Lesovedenie 1: 19-25.

NEGRI, V. and G. LEMMI (1998): Effect of selection and temperature stress on the production of $2 n$ gametes in Lotus tenuis. Plant Breeding 117: 345-349.

Nomura, K., J. NaKaJima, H. OHtA, H. KagaWA, H. TanAKA, T. UnUma, K. YamaUCHI and K. ARAI (2004): Induction of triploidy by heat shock in the Japanese eel Anguilla japonica. Fisheries Sci 70: 247-255.

Pécrix, Y., G. Rallo, H. Folzer, M. Cigna, S. Gudin and M. LE BRIS (2011): Polyploidization mechanisms: temperature environment can induce diploid gamete formation in Rosa sp. J Exp Bot 62(10): 3587-3597. 